\title{
Female harbor seal (Phoca vitulina) behavioral response to playbacks of underwater male acoustic advertisement displays
}

\author{
Leanna P Matthews ${ }^{\text {Corresp.. }}{ }^{1}$, Brittany Blades ${ }^{2}$, Susan E Parks ${ }^{1}$ \\ 1 Biology Department, Syracuse University, Syracuse, New York, United States \\ 2 Oregon Coast Aquarium, Newport, Oregon, United States \\ Corresponding Author: Leanna P Matthews \\ Email address: lematthe@syr.edu
}

During the breeding season, male harbor seals (Phoca vitulina) make underwater acoustic displays using vocalizations known as roars. These roars have been shown to function in territory establishment in some breeding areas and have been hypothesized to be important for female choice, but the function of these sounds remains unresolved. This study consisted of a series of playback experiments in which captive female harbor seals were exposed to recordings of male roars to determine if females respond to recordings of male vocalizations and whether or not they respond differently to roars from categories with different acoustic characteristics. The categories included roars with characteristics of dominant males (longest duration, lowest frequency), subordinate males (shortest duration, highest frequency), combinations of call parameters from dominant and subordinate males (long duration, high frequency and short duration, low frequency), and control playbacks of water noise and water noise with tonal signals in the same frequency range as male signals. Results indicate that overall females have a significantly higher level of response to playbacks that imitate male vocalizations when compared to control playbacks of water noise. Specifically, there was a higher level of response to playbacks representing dominant male vocalization when compared to the control playbacks. For most individuals, there was a greater response to playbacks representing dominant male vocalizations compared to playbacks representing subordinate male vocalizations, however, there was no statistical difference between those two playback types. Additionally, there was no difference between the playbacks of call parameter combinations and the controls. Investigating female preference for male harbor seal vocalizations is a critical step in understanding the harbor seal mating system and further studies expanding on this captive study will help shed light on this important issue. 
1 Female harbor seal (Phoca vitulina) behavioral response to playbacks of underwater male

2 acoustic advertisement displays

3

4 Leanna P. Matthews ${ }^{1}$, Brittany Blades ${ }^{2}$, Susan E. Parks ${ }^{1}$

5

$6 \quad{ }^{1}$ Biology Department, Syracuse University, Syracuse, New York, USA

$7 \quad{ }^{2}$ Oregon Coast Aquarium, Newport, Oregon, USA

8

9

10 Corresponding Author:

11 Leanna P. Matthews ${ }^{1}$

12

13 Email Address: lematthe@syr.edu

14

15

16

17

18

19

20

21

22 


\section{Abstract}

During the breeding season, male harbor seals (Phoca vitulina) make underwater acoustic displays using vocalizations known as roars. These roars have been shown to function in territory establishment in some breeding areas and have been hypothesized to be important for female choice, but the function of these sounds remains unresolved. This study consisted of a series of playback experiments in which captive female harbor seals were exposed to recordings of male roars to determine if females respond to recordings of male vocalizations and whether or not they respond differently to roars from categories with different acoustic characteristics. The categories included roars with characteristics of dominant males (longest duration, lowest frequency), subordinate males (shortest duration, highest frequency), combinations of call parameters from dominant and subordinate males (long duration, high frequency and short duration, low frequency), and control playbacks of water noise and water noise with tonal signals

36 in the same frequency range as male signals. Results indicate that overall females have a

37 significantly higher level of response to playbacks that imitate male vocalizations when compared to control playbacks of water noise. Specifically, there was a higher level of response to playbacks representing dominant male vocalization when compared to the control playbacks. For most individuals, there was a greater response to playbacks representing dominant male

41 vocalizations compared to playbacks representing subordinate male vocalizations, however, 42 there was no statistical difference between those two playback types. Additionally, there was no 43 difference between the playbacks of call parameter combinations and the controls. Investigating 44 female preference for male harbor seal vocalizations is a critical step in understanding the harbor 45 seal mating system and further studies expanding on this captive study will help shed light on 46 this important issue. 


\section{Introduction}

Acoustic communication is a critical component for reproductive success in a wide range

of species: males can use reproductive signals to attract females or defend territories against other males (for reviews, see Searcy and Andersson, 1986 and Andersson, 1994). Acoustic reproductive displays have several advantages over visual signals in low visibility habitats, such

as areas of dense foliage, underwater, or under low light conditions at night. For instance, signalers can use acoustic signals to rapidly transmit a large amount of information to potential receivers, and the animals do not have to see each other in order to communicate (for review, see Endler, 1993).

Female preference for acoustic signals plays an important role in sexual selection (Andersson, 1994). Females of some species have been shown to prefer signal traits that reflect honest indicators of male size, dominance status, or energetic reserves. For example, female red deer (Cervus elaphus) prefer calls with a lower frequency, which correspond to males of larger size (Charlton, Reby \& McComb, 2007). Female tungara frogs (Physalaemus pustulosus) also prefer calls with a lower frequency, also indicating a preference for larger males (Ryan, 1980). Female Hermann's tortoises (Testudo hermanni) prefer fast-rate acoustic displays, which are related to hematocrit levels in males and represent high quality mates (Galeotti et al., 2005). Females have also been shown to prefer males who demonstrate a higher rate of signal output. In red deer, females show preference for higher calling rates, which possibly correspond to male quality (McComb, 1991). A preference for high calling rates has also been seen in Gulf Coast toads (Bufo valliceps) (Wagner \& Sullivan, 1995). Likewise, female grey mouse lemurs (Microcebus murinus) prefer higher calling activity, which corresponds to the relative dominance status of the male (Craul, Zimmermann \& Radespiel, 2004). Females of some species, such as 
70 the gray tree frog (Hyla versicolor) (Gerhardt et al., 2000), show preference for calls that have a

71 longer duration, which is a reliable indicator of energetic expenditure.

The physics of the underwater environment, specifically the incompressible nature of

73

74

75

76

77

78

79

80

81

82

83

84

85

86

87

88

89

90

91

92

water compared to air, allows for much more efficient sound propagation than in air. Sound

travels approximately $340 \mathrm{~m} / \mathrm{s}$ in air, while it can travel around $1500 \mathrm{~m} / \mathrm{s}$ in seawater, depending on temperature and salinity. Additionally, visual communication is difficult in the underwater environment, as it is light-limited and individuals need to maintain a line of sight for effective signaling. Therefore, species that spend all or most of their lives underwater, such as marine mammals, have evolved to rely on acoustic communication for many behaviors, including reproductive advertisement displays.

Harbor seals are a commonly occurring marine mammal species from the pinniped group that breed underwater. Previous studies have shown that select males establish and hold territories during the breeding season (Van Parijs et al., 1997, 2000; Hayes et al., 2004a). However, not all males hold territories and it does not necessarily correspond to higher reproductive success for individual male harbor seals (Coltman, Bowen \& Wright, 1998, 1999; Hayes et al., 2006). During the breeding season, harbor seal males also produce underwater acoustic cues, known as roars. These signals are low in frequency $(78-1,300 \mathrm{~Hz})$ and can be up to 10 seconds in duration (Hanggi \& Schusterman, 1994; Van Parijs, Hastie \& Thompson, 2000; Matthews et al., 2017). Nicholson (2000) studied male-male interactions of harbor seals in Monterey Bay, CA from various age groups and hypothesized that subordinate males, males vocalizing alone, have roars that are shorter in duration and higher in frequency, while dominant males, males that are attended by other males, have roars with longer duration and lower frequency. This prediction is consistent with studies of other mammalian species with older, 
93 dominant males producing longer, and lower frequency signals (e.g. Vannoni \& McElligott,

94 2008; Wyman et al., 2012). There were also less frequent observations of intermediate

95 vocalizations, i.e., high frequency, long duration, by males that were only occasionally attended

96 (Nicholson, 2000). A recent publication on harbor seal vocalizations from a population in

97 British Columbia, Canada indicates that male vocalizations form a continuum, with a distribution

98 of both duration and frequency of male vocalizations (Nikolich et al., 2016). This aligns with the

99 Nicholson (2000) study, which indicated a range of characteristics for roar vocalizations, with

100 hypothesized 'dominant' and 'subordinate' males representing the extremes of this continuum of

101 vocal parameters.

102 A previous study demonstrated that roars were important for underwater territory

103 establishment by males (Hayes et al., 2004b). In this study, wild male harbor seals in Elkhorn

104 Slough, CA were exposed to three acoustic stimuli based on the results of Nicholson (2000):

105 long duration and low frequency roars (dominant male signals), short duration and high

106 frequency roars (subordinate male signals), and ambient water noise (control) (Hayes et al.,

107 2004b). Male harbor seals responded most aggressively to stimuli representing signals produced

108 by subordinate male roar vocalizations (Hayes et al. 2004). There were no observed responses

109 by females to any of the stimuli presented in the study, however it is hypothesized that the roars

110 may also influence female preference for potential mates (Hayes et al., 2004b). It is possible that

111 females are, in fact, responding to these male calls and have a preference for specific

112 characteristics of acoustic signals, but this behavior has yet to be observed. The studies by

113 Nicholson (2000) and Hayes et al. (2004b) served as the basis for the playback experiments

114 described here. 
A common approach for studying female response and preference for acoustic cues is via

116 playbacks (e.g.: Ryan, 1980; Hedrick, 1986; Searcy \& Andersson, 1986; Catchpole, 1987;

117 McComb, 1991). Previous playback experiments have investigated call function in a variety of

118 marine mammal species. In the first playback to marine mammals in the field, Watkins \&

119 Schevill (1968) played back recorded Weddell seal (Letonychotes weddellii) calls to male

120 Weddell seals in order to test the call function of various vocalizations. They found that high

121 quality recordings of conspecifics caused the subjects to respond acoustically, but they also noted

122 that the recordings did not attract seals and that subsequent playbacks elicited less of a response

123 (Watkins \& Schevill, 1968). Other playbacks to cetaceans, including humpback whales

124 (Megaptera novaeangliae) (Tyack, 1983; Mobley, Herman \& Frankel, 1988), southern right

125 whales (Eubalaena australis) (Clark \& Clark, 1980), and North Atlantic right whales (Eubalaena

126 glacialis) (Parks, 2003), have tested reactions to conspecific calls and artificial calls. Tyack

127 (1983) found that singing humpback whales ceased vocal activity and moved away in response

128 to playbacks of humpback whale social sounds, and Mobley, Herman \& Frankel (1988) found

129 that males approached the playback speaker when sounds of sexually mature females were

130 played. In right whales, playbacks have indicated that southern right whales are able to

131 differentiate between calls of conspecifics and humpback whales (Clark \& Clark, 1980) and

132 North Atlantic right whales respond to playbacks of calls produced during right whale social

133 interactions (Parks, 2003). There have also been additional playbacks to various pinnipeds that

134 have investigated caller recognition: subantarctic fur seal (Arctocephalus tropicalis) females are

135 able to recognize the vocalizations of pups (Charrier, Methevon \& Jouventin, 2002), Australian

136 sea lion (Neophoca cinerea) pups can recognize the vocalizations of their mothers (Charrier,

137 Pitcher \& Harcourt, 2009), and northern fur seal (Callorhinus ursinus) mothers and pups can 
138 recognize vocalizations of each other, although there is higher energy expenditure on the part of

139 the pups (Insley, 2001). These studies indicate that playbacks are a powerful tool for studying

140 marine mammal behavior. Studying female responses to male acoustic signals in captivity is an

141 excellent way to add further insight into the underwater behavior of these marine mammal

142 species.

143 This study used playback experiments with captive individuals to investigate female

144 response to male breeding vocalizations in harbor seals. The playbacks tested whether females

145 approach male calls more than control signals that do not contain biologically significant signals.

146 Multiple combinations of male call parameters (duration and frequency) were used to determine

147 whether these parameters affected female preference. Based on playbacks to other marine

148 mammal species, we predict that female harbor seals will have a greater response to playbacks

149 with conspecific calls compared to a control. Additionally, based on previous work that

150 indicates that females prefer lower frequency and longer duration calls, it is likely that female

151 harbor seals will approach the playback speaker more often during playbacks of dominant male

152 harbor seal calls, which have a lower frequency and longer duration.

153

154 Methods

155 Playback experiments were conducted at the Oregon Coast Aquarium in Newport, OR in

156 the summer of 2015 and 2016 (Syracuse University IACUC Permit \#14-003). Five female

157 harbor seals were tested in the first year of trials and a subset of four female harbor seals were

158 tested again for the second year. The fifth individual was not tested in the second year because

159 she went into the molt early and would not enter the pool voluntarily. The individuals were all

160 reproductively mature, demonstrating signs of estrous in previous years, and ranged in age from 
1616 to 30 years (Table 1). Four of the five individuals were born in the wild and stranded as pups.

162 All were housed with male harbor seals when not isolated for the playback trials. Experiments

163 were conducted while the individuals were in estrous, with the exception of three individuals

164 during the 2015 season, who were tested after the molting period, which occurs after estrous.

165 Estrous was determined using visual cues, including the appearance of inflamed genitalia.

166 Recordings of male harbor seal roars were collected in Elkhorn Slough, CA during May

167 2015. Recordings were made in close proximity to a single territorial individual to obtain a

168 series of high quality calls. Close proximity was assumed given that a subset of 20 calls had a

169 signal-to-noise ratio $>10 \mathrm{~dB}$. The recordings were divided into segments that each contained

170 five roars. The duration and frequency of the roars were adjusted in Adobe Audition to create

171 signals for the playback experiments. A total of 200 roars were modified as test signals.

172 Signals were created to test combinations of male call parameters. Two groups of

173 playbacks represented the extremes of calls found in nature (Figure 1): one for subordinate male

174 roars (short duration, high frequency) $(\mathrm{SH})$, and the other for dominant male roars (long

175 duration, low frequency) (LL). These signals mimicked those used in the playback experiments

176 of Hayes et al. (2004b). The "subordinate" playbacks consisted of roars that were less than $2.5 \mathrm{~s}$

177 (mean \pm SD: $2.10 \pm 0.05 \mathrm{~s}$ ) and had a minimum frequency of greater than $220 \mathrm{~Hz}(\mathrm{mean} \pm \mathrm{SD}$ :

$178247.30 \pm 8.80 \mathrm{~Hz}$ ) (Nicholson, 2000; Hayes et al., 2004b). The "dominant" roars were greater

179 than 3.0 seconds in length (mean \pm SD: $3.33 \pm 0.09 \mathrm{~s}$ ) and a minimum frequency of less than 200

$180 \mathrm{~Hz}($ mean \pm SD: $178.19 \pm 8.63 \mathrm{~Hz}$ ) (Nicholson, 2000; Hayes et al., 2004b). The other two

181 groups of playbacks represented combinations of the extremes of call parameters found in

182 subordinate and dominant roars - short duration, low frequency (SL) (mean \pm SD: $2.14 \pm 0.66 \mathrm{~s}$

183 and $156.27 \pm 45.45 \mathrm{~Hz}$ ) and long duration, high frequency $(\mathrm{LH})(\mathrm{mean} \pm \mathrm{SD}: 3.54 \pm 1.08 \mathrm{~s}$ and 
$184264.70 \pm 62.61 \mathrm{~Hz}$ ). These call parameter combinations are less common in nature (Nicholson,

185 2000) and these playbacks were used to tease out the acoustic characteristics to which females

186 respond most strongly.

187 A total of five playback files were made for each group of playback signals. Each file

188 consisted of 1-2 minutes of active playback that contained five roars based on the natural roar

189 timing of the recorded individual, and 1 minute of silence, when no roars were present. The call

190 intervals during the active playback varied slightly between files, with an average interval of

$19112.15 \pm 8.95$ seconds (mean \pm SD). This series of active playback and silence was repeated eight

192 times for a total of approximately 20 minutes.

193 Two additional groups of playback files were created as controls. The first control (W)

194 consisted of only water noise recorded in Elkhorn Slough and contained no biologically

195 significant sounds related to mating and territoriality. The secondary control (WT) was added as

196 an additional control in the second year of experiments and consisted of water noise with an

197 occasional synthetic tonal sound that was similar in frequency and duration to harbor seal roars.

198 This tonal sound contained no biologically significant information and was used to ensure that

199 female harbor seals were responding to the roar vocalizations in the experimental trials, rather

200 than the occurrence of novel sounds.

201 Each individual was exposed to one playback file per day for three to four consecutive

202 days, depending on the year. Three playbacks stimuli were used in the first year of experiments

203 (LL, SH, and W) and four stimuli were used during the second year (SL, LH, W, and WT).

204 Playbacks were arranged in a randomized block design, with three or four treatments (i.e.,

205 playbacks) and four or five blocks (i.e., individuals), depending on the year, and each subject

206 was exposed to a unique series of playbacks to avoid pseudoreplication. All trials were 
207 conducted in the same enclosure with only one individual tested at a time. The individual was

208 allowed in to the testing pool prior to the start of the playback and playbacks began after the

209 individual had been swimming for at least three minutes and aquarium personnel had left the

210 enclosure. Hunger state was not controlled for and no food rewards were given during the trials.

211 An underwater speaker (Lubell Labs LL916, frequency response: $200 \mathrm{~Hz}-23 \mathrm{kHz}( \pm 10$

$212 \mathrm{~dB}$ at $500 \mathrm{~Hz}-21 \mathrm{kHz}))$ was lowered approximately $1.5 \mathrm{~m}$ into the pool directly next to the

213 wall. The speaker was housed in a PVC cage and was positioned in the same place for every

214 trial. The speaker was connected to an amplifier (Dual XPA2100, frequency response: $\pm 3 \mathrm{~dB}$ at

$21520 \mathrm{~Hz}-20 \mathrm{kHz}$ ), and the amplifier was connected to an iPod, which was pre-loaded with the

216 playback files. Received levels were measured throughout the pool at multiple depths to ensure

217 that the playbacks were approximately equal in loudness to estimates of vocalization source

218 levels (155 dB re $1 \mu \mathrm{Pa}, \mathrm{C}$. Reichmuth, personal communication). Measured levels of the roars

219 in the playbacks ranged from 149 to $156 \mathrm{~dB}$ re $1 \mu \mathrm{Pa}$ rms. Since the playback experiments, more

220 recent studies have shown that the average loudness of harbor seal vocalizations is 144 to $145 \mathrm{~dB}$

221 re $1 \mu \mathrm{Pa}$ rms and range from 129 to $149 \mathrm{~dB}$ re $1 \mu \mathrm{Pa}$ rms (Casey, Sills \& Reichmuth, 2016;

222 Matthews et al., 2017). A GoPro camera (HERO4 Silver) was used to record all of the trials.

223 The camera was placed on an overlook above the enclosure (approximately $5 \mathrm{~m}$ elevation),

224 which allowed for full coverage of the playback pool, and the location of the camera was the 225 same for all the trials.

226 Video footage was used to complete behavioral sequencing for each of the playback

227 experiments. The numbers of approaches to the playback speaker were counted as a proxy for

228 female response. Approaches were defined as a deliberate investigation of the speaker. This

229 included any touching of the speaker with the vibrissae or curious examination of the PVC 
230 apparatus. The amount of time spent at the speaker for each approach was also measured. If a

231 female approached the speaker, left, and approached again quickly, it was considered two

232 separate approaches.

233 A series of Kruskal-Wallis tests were used to compare the number of approaches between

234 playbacks with signals and control playbacks to determine if females were attracted to male calls

235 in general. Three separate Kruskal-Wallis tests were run: one for a combined data set for both

236 years of playback experiments, one for the first year of experiments, and one for the second year

237 of experiments. Then, the numbers of approaches to the playback speaker for the different

238 categories (first year of playbacks: LL, SH, W; second year of playbacks: SL, LH, W, WT) were

239 compared using a nonparametric Friedman's test to test for preference between the playback

240 types and account for differences between individuals. Post hoc comparisons using the

241 Wilcoxon-Nemenyi-McDonald-Thompson test were used to further investigate significant

242 comparisons (Hollander, Wolfe \& Chicken, 2013). The two years of playbacks were analyzed

243 separately because only a subset of the individuals was tested in the second year. A second set

244 of Friedman's tests was used to compare the amount of time spent at the speaker. Statistical

245 analyses were done in R v. 3.2.3 (R Core Team, 2013).

247 Results

248 There was a significant difference between the numbers of approaches to the playback

249 speaker when projecting male vocalizations as compared to the controls for the combined data of

250 both years $(\mathrm{p}=0.003$ at $\alpha<0.05)$. When analyzing the years individually, the difference

251 between the number of approaches for playbacks with signals and playbacks with controls was 
252 significant for the first year of experiments ( $\mathrm{p}=0.009$, LL and SH vs. W), but not significant for

253 the second year of experiments ( $p=0.27$, SL and LH vs. W and WT).

254 Friedman's tests indicated an overall significant difference in the number of approaches

255 made to the different categories of playbacks for the first year of experiments (Figure 2a, $p=$

256 0.029). Female harbor seals approached the playback speaker significantly more during the LL

257 playback when compared to the control $(\mathrm{W})(\mathrm{p}=0.021)$. The maximum number of approaches

258 during LL male playbacks was 4, which was noted for two of the five individuals, and the

259 minimum number was 1 approach. No individuals approached the speaker during the control

260 (W) playback. There was no statistical difference between the number of approaches during the

261 SH and LL male playbacks ( $p=0.377)$ or the SH and control $(\mathrm{W})$ playbacks $(\mathrm{p}=0.367)$. For the

262 second year of playbacks, there was no difference in the number of approaches to the speaker for

263 any of the stimuli (SL, LH, W, and WT), with overall low numbers of approaches to all stimuli,

264 including controls (Figure $2 \mathrm{~b}, \mathrm{p}=0.733$ ). The maximum number of approaches was during the

265 LH playback, with two approaches. One individual approached the speaker once during this

266 playback and the other two individuals did not approach the speaker at all. Two individuals

267 approached the SL playback once, while the other two did not approach the speaker. Only one

268 individual approached the speaker during the W playback and one individual approached during

269 the WT playback, though the individuals who approached were different. The other three

270 females did not approach the speaker during either of the control playbacks (W or WT).

271 The results of the Friedman's tests for the amount of time spent at the speaker were

272 similar to the approach results (year one: $p=0.029$; year two: $p=0.782$ ). In the first year of

273 playbacks, approaches ranged from $1-13$ total seconds, with the longest approach times 
274 occurring during LL male playbacks. In the second year, approaches lasted from $4-10$ seconds.

275 A summary of the time spent at the speaker during each approach is available in Table 2.

276

277 Discussion

278 This study is the first to specifically investigate if 1) female harbor seals show interest in

279 male acoustic signals and 2) to test for potential female preference for different parameters of

280 male breeding vocalizations in harbor seals. In regards to the first goal of this paper, the

281 combined data from both years of playbacks, as well as only the data from the first year, indicate

282 that captive female harbor seals show significantly more interest in playbacks with male

283 vocalizations compared to controls. A previous study on male harbor seal response to playbacks

284 in the wild did not note any behavioral shifts in females (Hayes et al., 2004b), but the responses

285 made by females in our experiments were fairly brief and were only detectable because there was

286 a clear view to the bottom of the pool. It is possible that females did approach the playback

287 speaker in the previous study, but the approaches were undetectable to the researchers due to

288 turbidity of the water. There was no significant difference in response when comparing the call

289 parameter combination playbacks of the second year (SL and LH) to the controls (W and WT).

290 It is possible that both the lowest frequency and longest duration or the highest frequency and

291 shortest duration is necessary for females to respond to vocalizations and that the other

292 combinations of parameter extremes, which are less common in nature (Nicholson, 2000), are

293 less likely to elicit a response.

294 The numbers of approaches to the playback speaker were not significantly different

295 between the types of playbacks that contained male acoustic signals (year one: LL vs. SH, year

296 two: SL vs. LH). However, although not statistically significant, four out of five females did 
297 approach the playback speaker more during playbacks of dominant (LL) vocalizations compared 298 to playbacks of subordinate (SH) vocalizations. It is possible, but is not confirmed here, that the 299 roar vocalization may play a role in male-female communication during the breeding season,

300 with females using acoustic cues to make decisions on mate preference when other modalities,

301 such as sight and smell, are limited. Females from other species have been shown to prefer

302 vocalizations that are honest advertisements and denote a higher dominance rank (e.g.: Clutton-

303 Brock \& Albon, 1979; McComb, 1991; Craul, Zimmermann \& Radespiel, 2004; Galeotti et al.,

304 2005; Puechmaille et al., 2014). It is also possible that the statistical insignificance between the

305 LL and SH calls is representative of actual female responses, and there is no difference in

306 response level between the two. This may indicate that variability in roar vocalization

307 parameters are primarily for the purpose of male-male interactions and not a mechanism of 308 female preference.

309 Even though there was no statistically significant difference between any playback

310 stimuli in the second year of trials, there were differences in responses of individuals to the

311 different stimuli. For instance, Pinky responded more during the SL and LH trials compared to

312 either of the controls (W and WT), while Swap responded equally to the SL, LH, and WT, but

313 did not respond to the water noise control (W). Because of the variation in responses between

314 individuals, it is possible that there may be other information in the roars that is important for

315 female discrimination and preference.

316 It is also important to note that because different individuals were tested in the two years,

317 it is not possible to statistically compare the responses to the LL male playbacks and the

318 secondary control with the tonal signals (WT) using a Friedman's test. It would be of interest for 
319 future studies to further investigate these results, and to determine with certainty if females

320 respond more to biologically important information or novel acoustic stimuli.

321 In the first year of trials, only two individuals were confirmed to be in estrous during the

322 playback experiments. However, similar trends - an increase in the number of approaches

323 during the LL male playback compared to the SH and control playback (W) - were observed

324 between estrous and non-estrous individuals, with the exception of one individual. One female, 325 Pinky, approached the speaker more during the SH male playback compared to the LL male 326 playback. This could be due to a variety of factors. Firstly, she might have been unmotivated

327 due to lack of estrous and her approaches were purely based on curiosity. Secondly, Pinky was

328 the oldest of the test subjects and might not have as great an ability to discriminate acoustic

329 signals as younger individuals due to potential presbycusis, although hearing data were not 330 available for any of the individuals in this study.

$331 \quad$ Harbor seals inhabit a wide range and the vocal characteristics can vary between 332 populations (Van Parijs et al., 2003). All females, despite their origin, were exposed to roars 333 modified from an opportunistic data set of recordings made in California. It is possible that a 334 different set of acoustic characteristics would yield different responses by females based on their 335 genetic population of origin.

336 It is also possible that females were responding just to the presence of harbor seal 337 vocalizations, and not specifically the roar; this preference between vocalization types has not 338 been tested. However, the females in these trials did not investigate the playback speaker more 339 than during the controls except during the dominant male playbacks, indicating that the novelty 340 of a seal sound alone did not evoke a significantly stronger response. 


\section{Conclusions}

343 This study demonstrated that females appear to show interest in male calls. Future

344 studies should aim to confirm if female harbor seals show similar interest in male vocalizations

345 in the wild. The results also indicate preliminary evidence of a female preference for lower

346 frequency, longer duration signals. A two-choice test for female harbor seals would help further

347 parse out female responses to male acoustic signals.

348

\section{Acknowledgements}

350 The authors would like to thank the staff and volunteers of the Oregon Coast Aquarium

351 for their assistance with this project. We would also like to thank Alex Carbaugh-Rutland for his

352 help in data collection during the 2016 season. IACUC approval for the playback experiments

353 was provided by Syracuse University.

References

356

357

358

360

361

362

363

364

Andersson M. 1994. Sexual Selection. Princeton, NJ: Princeton University Press.

Casey C, Sills J, Reichmuth C. 2016. Source-Level Estimates for Harbor Seals and Implications for Estimating Communication Space. Presented at the Fourth International Conference on the Effects of Noise on Aquatic Life, Dublin, Ireland.

Catchpole CK. 1987. Bird Song, Sexual Selection and Female Choice. Trends in Ecology \& Evolution 2:94-97.

Charlton BD, Reby D, McComb KE. 2007. Female red deer prefer the roars of larger males. Biology Letters 3:382-385. doi: 10.1098/rsbl.2007.0244

Charrier I, Mathevon N, Jouventin P. 2002. How does a fur seal mother recognize the voice of 
365 her pup? An experimental study of Arctocephalus tropicalis. The Journal of Experimental

366 Biology 205:603-612.

367 Charrier I, Pitcher BJ, Harcourt RG. 2009. Vocal recognition of mother by Australian sea lion

368 pups: individual signature and environmental constraints. Animal Behaviour 78:1127-1134.

369 doi: 10.1016/j.anbehav.2009.07.032

370 Clark CW, Clark JM. 1980. Sound playback experiments with Southern right whales (Eubalaena

371 australis). Science 207:663-665.

372 Clutton-Brock TH, Albon SD. 1979. The Roaring of Red Deer and the Evolution of Honest

373 Advertisement. Behaviour 69:145-170.

374 Coltman DW, Bowen WD, Wright JM. 1998. Male mating success in an aquatically mating

375 pinniped, the harbour seal (Phoca vitulina), assessed by microsatellite DNA markers.

376 Molecular Ecology 7:627-638. doi: 10.1046/j.1365-294x.1998.00373.x

377 Coltman DW, Bowen WD, Wright JM. 1999. A multivariate analysis of phenotype and paternity

378 in male harbor seals, Phoca vitulina, at Sable Island, Nova Scotia. Behavioral Ecology

$379 \quad$ 10:169-177. doi: 10.1093/beheco/10.2.169

380 Craul M, Zimmermann E, Radespiel U. 2004. First experimental evidence for female mate

381 choice in a nocturnal primate. Primates 45:271-274. doi: 10.1007/s10329-004-0097-5

382 Endler JA. 1993. Some General Comments on the Evolution and Design of Animal

383 Communication Systems. Philosophical Transactions of the Royal Society of London B

384 Biological Sciences 340:215-225.

385 Galeotti P, Sacchi R, Rosa DP, Fasola M. 2005. Female preference for fast-rate, high-pitched

386 calls in Hermann's tortoises Testudo hermanni. Behavioral Ecology 16:301-308.

387 Gerhardt HC, Tanner SD, Corrigan CM, Walton HC. 2000. Female preference functions based 
on call duration in the gray tree frog (Hyla versicolor). Behavioral Ecology 11:663-669.

389

390

391

392

393

394

Hanggi EB, Schusterman RJ. 1994. Underwater acoustic displays and individual variation in male harbour seals, Phoca vitulina. Animal Behaviour 48:1275-1283.

Hayes SA, Costa DP, Harvey JT, Le Boeuf BJ. 2004a. Aquatic mating strategies of the male Pacific harbor seal (Phoca vitulina richardii): Are males defending the hotspot? Marine Mammal Science 20:639-656. doi: 10.1111/j.1748-7692.2004.tb01184.x

Hayes SA, Kumar A, Costa DP, Mellinger DK, Harvey JT, Southall BL, Le Boeuf BJ. $2004 b$. Evaluating the function of the male harbour seal, Phoca vitulina, roar through playback experiments. Animal Behaviour 67:1133-1139. doi: 10.1016/j.anbehav.2003.06.019

Hayes SA, Pearse DE, Costa DP, Harvey JT, Le Boeuf BJ, Garza JC. 2006. Mating system and reproductive success in eastern Pacific harbor seals. Molecular Ecology 15:3023-3034. doi: 10.111/j.1365-294x.2006.02984.x

Hedrick AV. 1986. Female Preferences for Male Calling Bout Duration in a Field Cricket. Behavioral Ecology and Sociobiology 19:73-77.

Hollander M, Wolfe DA, Chicken E. 2013. Nonparametric statistical methods. John Wiley \& Sons.

Insley SJ. 2001. Mother-Offspring vocal recognition in northern fur seals is mutual but asymmetrical. Animal Behaviour 61:129-137.

Matthews LP, Parks SE, Fournet MEH, Gabriele CM, Womble JN, \& Klinck H. 2017. Source levels and call parameters of harbor seal breeding vocalizations near a terrestrial haulout site in Glacier Bay National Park and Preserve. Journal of the Acoustical Society of America 141:EL274-EL280. doi: http://dx.doi.org/10.1121/1.4978299

McComb KE. 1991. Female choice for high roaring rates in red deer, Cervus elaphus. Animal 
412 Mobley JR Jr, Herman LM, Frankel AS. 1988. Responses of wintering humpback whales

413 (Megaptera novaeangliae) to playback of recordings of winter and summer vocalizations

414 and of synthetic sound. Behavioral Ecology and Sociobiology 23:211-223.

415 Nicholson T. 2000. Social Structure and Underwater Behavior of Harbor Seals in Southern

416 Monterey Bay, California. MS Thesis, San Francisco State University.

417 Nikolich K, Frouin-Mouy H, Acevedo-Gutierrez A. 2016. Quantitative classification of harbor

418 seal breeding calls in Georgia Strait, Canada. Journal of the Acoustical Society of America

419 140:1300-1308. doi: $10.1121 / 1.4961008$

420 Parks SE. 2003. Response of North Atlantic Right Whales (Eubalaena glacialis) to Playback of

421 Calls Recorded From Surface Active Groups in Both the North and South Atlantic. Marine

422 Mammal Science 19:563-580. doi: 10.1111/j.1748-7692.2003.tb01321.x

423 Puechmaille SJ, Borissov IM, Zsebok S, Allegrini B, Hizem M, Kuenzel S, Schuchmann M,

424 Teeling EC, Siemers BM. 2014. Female Mate Choice Can Drive the Evolution of High

425 Frequency Echolocation in Bats: A Case Study with Rhinolophus mehelyi. PLoS ONE

426 9:e103452-9. doi: 10.1371/journal.pone.0103452

427 R Core Team. 2013. R: A language and environment for statistical computing.

428 Ryan MJ. 1980. Female Mate Choice in a Neotropical Frog. Science 209:523-525.

429 Searcy WA, Andersson M. 1986. Sexual Selection and the Evolution of Song. Annual Review of $430 \quad$ Ecology and Systematics 17:507-533.

431 Tyack PL. 1983. Differential response of humpback whales, Megaptera novaeangliae, to 432 playback of song or social sounds. Behavioral Ecology and Sociobiology 13:49-55.

433 Van Parijs SM, Corkeron PJ, Harvey J, Hayes SA, Mellinger DK, Rouget PA, Thompson PM, 
Wahlberg M, Kovacs KM. 2003. Patterns in the vocalizations of male harbor seals. Journal of the Acoustical Society of America 113:3403-3410. doi: 10.1121/1.1568943

436 437

438

440

441

442

443

444

445

446

447

448

449

450

451

452

453

454

455

Van Parijs SM, Hastie GD, Thompson PM. 2000. Individual and geographical variation in display behaviour of male harbour seals in Scotland. Animal Behaviour 59:559-568. doi:

$$
\text { 10.1006/anbe. } 1999.1307
$$

Van Parijs SM, Janik VM, Thompson, PM. 2000. Display-are size, tenure length, and site fidelity in the aquatically mating male harbour seal, Phoca vitulina. Canadian Journal of Zoology 78:2209-2217. doi: 10.1139/cjz-78-12-2209

Van Parijs SM, Thompson PM, Tollit DJ, Mackay A. 1997. Distribution and activity of male harbor seals during the mating season. Animal Behavior 54:35-43. doi:

$$
\text { 10.1006/anbe. } 1996.0426
$$

Vannoni E, McElligott AG. 2008. Low Frequency Groans Indicate Larger and More Dominant Fallow Deer (Dama dama) Males. PLoS ONE 3:e3113-8. doi:

$$
\text { 10.1371/journal.pone.0003113 }
$$

Wagner WE Jr, Sullivan BK. 1995. Sexual selection in the Gulf Coast toad, Bufo valliceps: female choice based on variable characters. Animal Behaviour 49:305-319.

Watkins WA, Schevill WE. 1968. Underwater playback of thier own sounds to Letonychotes (Weddell seals). Journal of Mammalogy 49:287-296.

Wyman MT, Mooring MS, McCowan B, Penedo MCT, Reby D, Hart LA. 2012. Acoustic cues to size and quality in the vocalizations of male North American bison, Bison bison. Animal Behaviour 84:1381-1391. doi: 10.1016/j.anbehav.2012.08.037 


\section{Table $\mathbf{1}$ (on next page)}

List of Individuals from playback experiments

Individuals used in playback experiments, their approximate dates of birth, life history information, and whether or not they were in estrous during the playbacks for either year of experiments. Boots was not included in the 2016 experiments. 
1

\begin{tabular}{ccccc}
\hline Individual & DOB & Life History & Estrous & Estrous \\
& & & $\mathbf{2 0 1 5}$ & $\mathbf{2 0 1 6}$ \\
\hline Boots & January 1988 & Wild born (California) & No & -- \\
Pinky & June 1986 & Wild born (Washington) & No & Yes \\
Swap & August 1991 & Wild born (Washington) & Yes & Yes \\
Tater & March 1994 & Captive born (California) & No & Yes \\
Tazzy & 2009 & Wild born (British Columbia) & Yes & Yes \\
\hline
\end{tabular}

2

3

4

5

6

7

8

9

10 


\section{Table 2 (on next page)}

Summary statistics of the time spent investigating the speaker

The average time spent investigating the speaker during each approach and the range of times observed for approaches for each trial during both years of playback experiments. The NA values in the range column correspond to trials for which there was only one approach. The * indicates individuals that were not in estrous during the playback experiments. 


\begin{tabular}{lccccccc}
\hline Year & \multicolumn{3}{c}{ Dominant } & \multicolumn{2}{c}{ Subordinate } & \multicolumn{2}{c}{ Control 1 } \\
\hline 2015 & Individual & Avg. (s) & Range (s) & Avg. (s) & Range (s) & Avg. (s) & Range (s) \\
\cline { 2 - 7 } & Boots* & 3.25 & $2-5$ & 2.33 & $2-3$ & 0.00 & 0.00 \\
& Pinky* & 3.50 & $1-6$ & 3.67 & $2-6$ & 0.00 & 0.00 \\
& Swap & 1.33 & $1-2$ & 0.00 & 0.00 & 0.00 & 0.00 \\
& Tater* & 3.00 & NA & 0.00 & 0.00 & 0.00 & 0.00 \\
& Tazzy & 6.75 & $2-13$ & 2.00 & NA & 0.00 & 0.00 \\
\hline
\end{tabular}

LF/Short

HF/Long

Control 1

Control 2

\begin{tabular}{cccccccccc}
2016 & Individual & Avg. $(s)$ & Range $(s)$ & Avg. $(s)$ & Range $(s)$ & Avg. $(s)$ & Range $(s)$ & Avg. $(s)$ & Range $(s)$ \\
\cline { 2 - 8 } & 3.00 & NA & 3.50 & $3-4$ & 0.00 & 0.00 & 0.00 & 0.00 \\
Pinky & 10.00 & NA & 4.00 & NA & 0.00 & 0.00 & 6.00 & NA \\
Tater & 0.00 & 0.00 & 0.00 & 0.00 & 4.00 & NA & 0.00 & 0.00 \\
Tazzy & 0.00 & 0.00 & 0.00 & 0.00 & 0.00 & 0.00 & 0.00 & 0.00 \\
\hline
\end{tabular}

2 


\section{Figure 1}

Spectrograms of male roar vocalizations

Visual representations of male harbor seal vocalizations that have been modified to represent dominant males (A) and subordinate males (B) (spectrogram parameters: Hann window, 50\% overlap, discrete Fourier transform [DFT] size $=4096$ ).
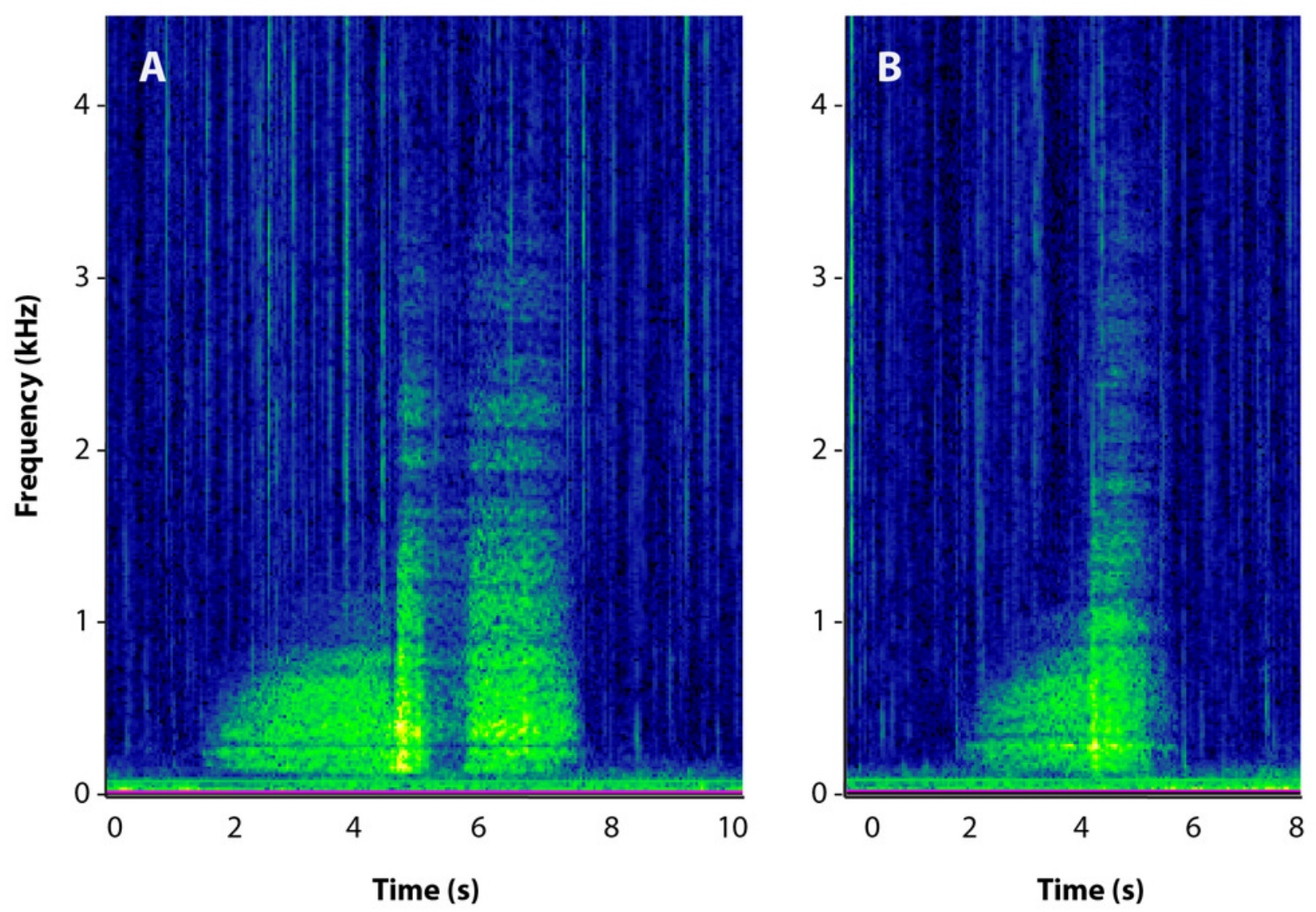
Figure 2

Results from playback experiments

Line graphs illustrating the number of approaches made to the playback speaker during the first year of playbacks (A) and second year of playbacks (B). Year one tested short duration, high frequency signals (SH), long duration, low frequency signals (LL), and a water noise control (W). Year two tested short duration, low frequency signals (SL), long duration, high frequency signals (LH), a water noise control (W), and a water noise control with tonal signals in the frequency range of male signals (WT).

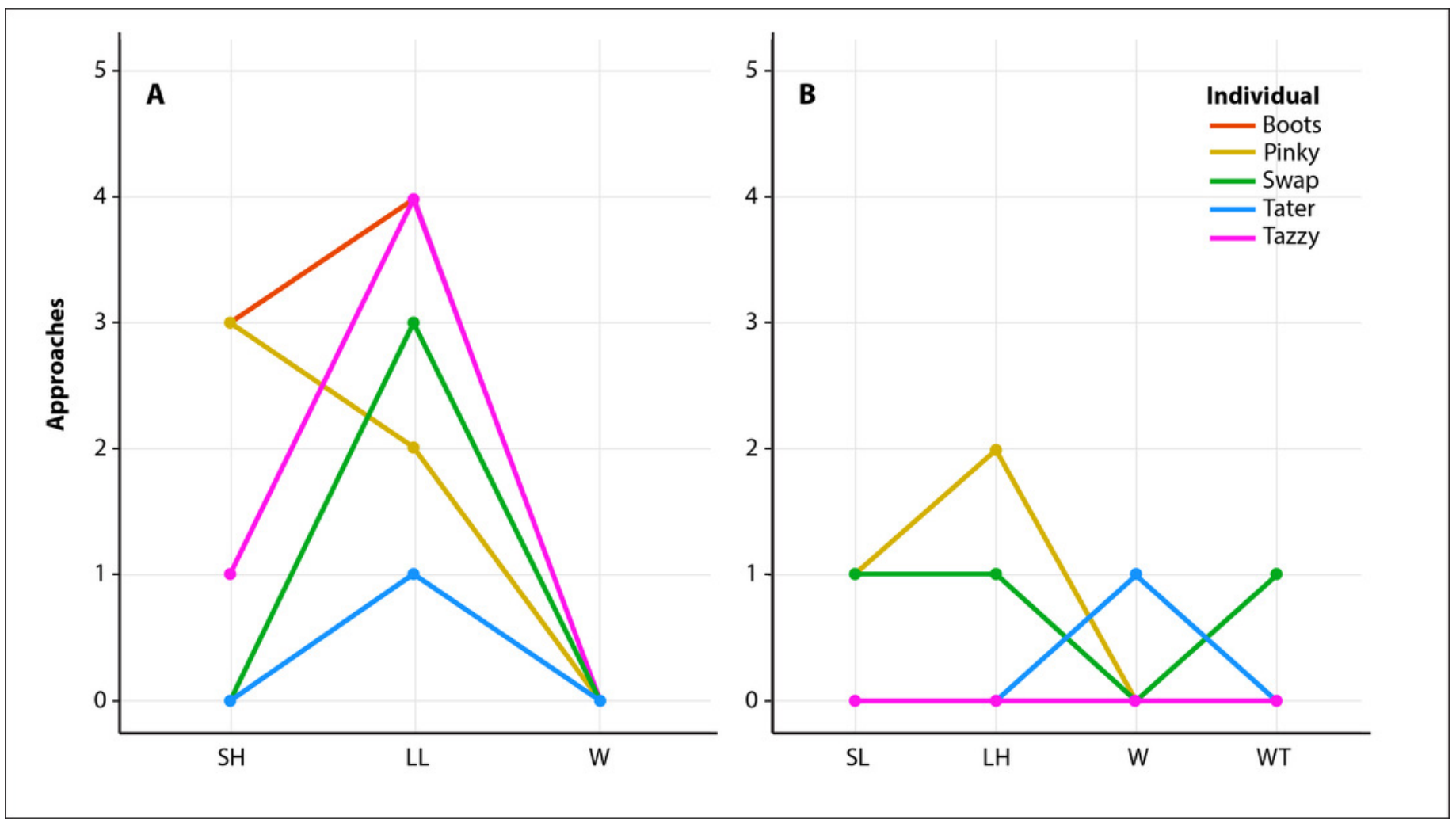

